\title{
Bio-mechanical Analysis of the Grapevine Cluster Thinning Task using Working Chair
}

\author{
Kyung Suk Lee, Hyo Cher Kim, Hye Seon Chae, Kyung Ran Kim, Dae Seop Lim
}

National Academy of Agricultural Science, RDA, Suwon, 441-857

\begin{abstract}
Objective: This study examined the effects of working chair that was developed for farmers who work in grapevine's cluster thinning. Background: Agricultural work involves some of the nation's highest occupational risk exposures. Fruit cultivation has been recognized as one of the most hazardous crops in which to work. Grapevine cluster thinning task involve activities related to the main risk factors associated with upper limb work-related musculoskeletal disorders. Method: An experiment was designed to test the working chair. Six healthy male(25.8 \pm 4.9 years) were selected as the subjects for this study. Electromyography(EMG) was used to monitor the muscles activity, and Electro-goniometer was used to measure the ranges of motions of the elbow, trunk and knee. Subjective test was also carried out to examine discomfort body parts and their pain intensity. A grapevine's working space was built for the experiment and working chair was installed on it. In order to examine the muscle activity and range of motion, subjects used to the working chair for 30 minutes for each experimental condition. Another test without working chair was also performed for comparison. \%MVC was used to quantify the level of muscle activity. Results: Decreases of muscle activity was found in all leg muscles and significant decrease of muscle activity was found in left Gastrocnemius. The range of motion of the trunk and knee also decreased when working chair used. Discomfort in lower back, thigh and shank region were reduced significantly. However, in upper limbs muscle activity tended to increase in working chair compared with conventional task. Conclusion: Improvement for cushion in seat back and pan required to reduce discomfort in buttocks. Application: Overall findings verified that the working chair might help to prevent upper limb and lower back MSDs based on the current study. These results can be practically used for work improvement for the grapevine growers to prevent MSDs.
\end{abstract}

Keywords: Grapevine cluster thinning, Working Chair, Biomechanical analysis, Ergonomic Intervention

\section{Introduction}

국내 농업인구의 감소, 고령화, 여성화 등 농업인력 조건 의 악화와 더불어, 비닐하우스 및 유리온실 등 시설농업 비 중의 증가로 인해 연중무휴의 노동조건으로 변화함에 따라 농업인의 건강상태가 악화되고 있다. 또한 농작업에서의 기 계화가 진전되었음에도 불구하고 여전히 인력작업에 의존하 는 비율이 높으며, 작물위주의 작업으로 인한 불편한 작업
자세, 반복작업, 과도한 힘, 장시간의 노동, 휴식시간의 부족 등 다수의 인간공학적 위험요인을 가지고 있어, 농부증, 근 골격계 질환 등 직업성 질환의 위험성이 상존하고 있다. 농 촌진흥청 연구(2004)에 따르면, 우리나라 농업인의 근골격 계 질환 자각 증상 호소율이 84 92\%에 이르고 이는 비농 업인에 비해 약 2.4 배 높은 수준이며, 과수 $(67 \%)$, 밭작물 (60\%), 축산(35\%) 등 작목별 증상 유병률에 차이가 있는 것으로 보고되었다. 또 다른 연구에서는 과수재배 농업인의 근골격계 증상 유병률이 $73.3 \%$ 에 이르고 다리(47.7\%), 허

Corresponding Author: Dae Seop Lim. National Academy of Agricultural Science, RDA, Suwon, 441-857.

Mobile: 010-4653-5883, E-mail: daesup@korea.kr

Copyright@2011 by Ergonomics Society of Korea(pISSN:1229-1684 eISSN:2093-8462). All right reserved. 
리(40.9\%), 어깨(36.6\%) 등 신체 부위별로 증상 유병률의 차이가 있었다. 특히, 포도재배 농업인의 근골격계 증상 유 병율이 매우 높은 수준으로 보고되고 있어, 이에 대한 원인 파악과 개선대책이 시급히 필요하다(RRDI, 2006).

포도재배 작업의 작업환경, 노동부담 및 작업자의 건강 에 관한 연구는 많이 보고되고 있다(Kim, H.N. and K.M. Hwang, 1991; Choi et al., 1998; Choi et al., 2002; Lee et al., 2008). 포도재배 농가는 다른 농가와 비슷하게 노동인 구의 고령화와 부녀화라는 기본적인 문제를 안고 있고, 수확 작업시 불편한 작업자세로 인해 목과 어깨 부위에 대해 다른 농가보다 높은 통증 호소율을 보여 줄뿐 아니라, 특히 여름 철에 정기적으로 서열에 노출되어 있어, 열 장해로 인해 작 업자의 건강과 작업능률이 모두 떨어지는 부정적인 영향을 받고 있다(Choi et al., 1998; Choi et al., 2002). 일년 주기 의 포도재배 작업 중 가장 몸이 아픈 작업은 봉지 씨우기와 수확작업이며, 가장 긴 시간이 소요되는 작업도 수확작업이 라 알려져 있다(Kim, H.N. and K.M. Hwang, 1991). 그리 고 포도 순치기 작업과 알솎기 작업의 경우는 장시간 반복 적인 작업이 많아 목, 어깨 등에 부담을 주는 작업으로 시급 히 개선이 필요하다고 지적되고 있다. 게다가 경사지에서의 포도 알솎기 작업은 엉거주춤한 상태에서 이루어져야 하므 로 더욱 작업부담이 높다(Kim et al., 2008). 포도 작목을 대상으로 한 Lee(2008) 등의 연구에 의하면, 표준화된 작 업자세 위험도 평가를 통해 분석한 결과 포도 송이따기, 전 지전정 및 알솎기 작업이 고위험 작업으로 분류되었으며, 어 깨가 들리는 자세(45도 이상), 손목의 과도한 굽힘(15도 이상/-15도 이하), 강하게 쥐는 힘(Power/pinch Grip) 및 지속적으로 서있는 자세(4시간이상)가 근골격계 질환과 관 련된 인간공학적 위험요인들로 제시되었다.

최근에는 포도 수확작업 및 전지전정 작업의 작업부담을 줄이고, 작업효율을 높이기 위한 연구와 근골격계 질환을 예 방하기 위한 보조도구 개발 및 인간공학적 작업환경 개선에 관한 연구가 진행되고 있다. Wakula(2000) 등은 포도 순치 기, 전지정전 및 수확작업에 일반적으로 쓰이는 정전가위를 대상으로 가위의 날 또는 손잡이의 각도와 형태별로 생체역 학적 평가를 내렸으며, 손목의 부담을 완화시키는 정도를 평 가하였다. Duraj(1999) 등은 포도 수확작업시 인간공학적 유해요인을 줄이는 포도수확 보조도구들 - 착용감을 증대시 킨 손잡이가 부착된 경량 운반상자와 수확용 칼 손잡이 - 을 개발하여 안전성 및 생산성을 평가하였다. Kato(2006) 등은 와인포도농가에서 흔히 이용되는 5종류 Trellis System에 서 정전 전지작업시 손목 및 허리의 근골격계 위험도를 평 가함으로써 이 중 $\mathrm{VSP}$ 시스템을 이용한 작업방식이 최적이 라고 제시하였다. 또한 $\operatorname{Kim}(2009)$ 등은 포도 순치기 작업 을 개선하기 위해 레일이동형 작업의자를 개발하여, 근전도
와 심박측정기를 이용하여 생리학적 부담평가를 하고, RULA 와 REBA를 이용하여 작업자세를 평가하였다.

하지만, 알솎기 작업에 대한 근골격계 위험성 및 위험요인 이 제시되어 개선이 요구됨에도 불구하고, 이를 저감하기 위 한 개선방안에 관한 연구는 미흡한 실정이다. 현재 이 작업 을 개선하기 위해 작업의자가 개발되어 농가에 보급되어 이 용되고 있다. 하지만 이 보조도구의 작업부담 경감효과가 명확히 밝혀져 있지 않은 상황이다.

따라서 본 연구는 포도 알솎기 작업의자의 작업부담 경감 효과를 생체역학적 분석방법을 이용하여 정량적으로 평가하 고, 향후 보조도구의 개선사항을 도출하는데 목적이 있다.

\section{Method}

\subsection{Subject}

본 연구에 참여한 피실험자들은 신체건강하고, 근골격계 관련 질환을 않지 않은 성인 남성 6 명이 참가하였다. 전체 피실험자의 평균 연령은 $25.8 \pm 4.9$ [세]이고, 신장 및 몸무 게의 평균은 각각 $175 \pm 1.4[\mathrm{~cm}], 70.3 \pm 14.5[\mathrm{~kg}]$ 이었다. 주요 신체계측 정보는 <표 1>과 같다. 그리고 모두 오른손 잡이이다.

Table 1. Anthropometric data of subjects

\begin{tabular}{c|r|l|l}
\hline Variable & Mean(SD) & Max & Min \\
\hline Age(years) & $25(4.9)$ & 33 & 20 \\
\hline Height $(\mathrm{cm})$ & $175(1.4)$ & 177 & 173 \\
\hline Weight $(\mathrm{kg})$ & $70.3(14.5)$ & 96.1 & 53.5 \\
\hline Sitting Height $(\mathrm{cm})$ & $87.8(9.6)$ & 95 & 69 \\
\hline Knee Height $(\mathrm{cm})$ & $45.9(1.9)$ & 48.5 & 43.6 \\
\hline Bi-deltoid Breadth $(\mathrm{cm})$ & $42.8(2.3)$ & 45.5 & 40.5 \\
\hline Hip Breadth $(\mathrm{cm})$ & $33.85(3.8)$ & 40.5 & 28.7 \\
\hline Functional grip reach(cm) & $74.5(1.7)$ & 77.6 & 73 \\
\hline Functional leg length $(\mathrm{cm})$ & $100.8(3.1)$ & 104 & 96 \\
\hline
\end{tabular}

\subsection{Selection of muscle}

포도 알솎기 작업의자를 이용한 작업 개선시 근육활동을 평가하기 위하여 어깨, 허리 및 하지 관련 4 개 근육을 선 정하였다. 평가 근육으로는 견갑골 회전, 어깨 외전 및 목 과 머리의 신전을 담당하는 승모근(Trapezius)과 척추의 신전을 담당하는 척추 세움근(Erector Spine) 과 대퇴의 신 전 및 다리(무름)의 굴곡과 신전을 관장하는 대퇴사두근 
(Rectus Femoris)과 발목의 신전, 무릎의 굴곡과 발목의 굴절을 관장하는 비복근(Gastrocnimus)을 선정하였다. 그 림 1 은 본 연구에서 선정한 4 가지 근육과 근전도 분석을 위 한 electrode 부착위치를 보여준다. 근전도의 부착위치는 $\mathrm{NIOSH}$ (1992)의 문헌을 참조하였다.

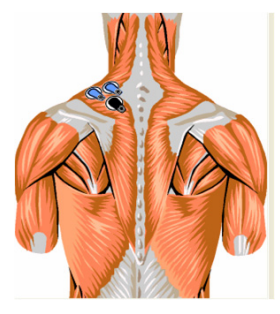

(a)

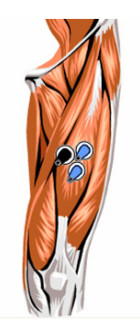

(c)

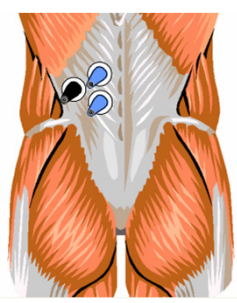

(b)

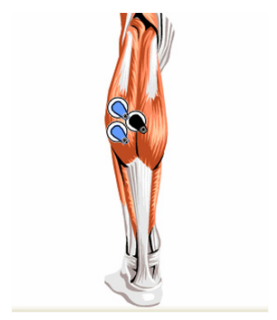

(d)
Figure 1. Muscles and position of EMG electrode [(a) Trapezius, (b) Erector Spine, (c) Rectus Femoris, (d) Gastrocnimus]

\subsection{Experimental equipment}

현재 시판중인 포도 알솎기 작업의자의 형태는 [그림 2] 와 같다. 이 작업의자는 유압식 높이조절장치로 의자높이 조절이 자유로우며, 경사도에 맞춰 의자 앞, 뒤 높이 조절 이 가능한 특징이 있다. 본 연구에서는 주요 관절(팔꿈치, 몸통 및 무릎)의 각도변화를 측정하기 위해서 전자각도기 (Electro-goniometer, Biometrics Ltd, USA) 를 사용하였 고, 센서로부터의 데이터는 DataLink의 Data Acquisition System을 통하여 수집되고, Biometrics Analysis Software 를 이용하여 작업시간 동안의 3 개 관절 각각의 각 운동 분 포를 분석하였다.

근육활동을 평가하기 위해 8채널 근전도(MEGA 6000P, Mega Electronics Ltd., Finland)가 사용되었다. 실험참가 자의 표면전극의 부착위치에 alcohol로 피부표면의 노폐물 을 닦아내고, 8개 Channel의 표면전극을 부착하였으며, 팔 꿈치, 몸통 및 무릎관절에 전자각도기를 부착하였다[그림 3].

근전도 신호의 정규화를 목적으로 문헌을 참조하여 $\mathrm{MVC}$

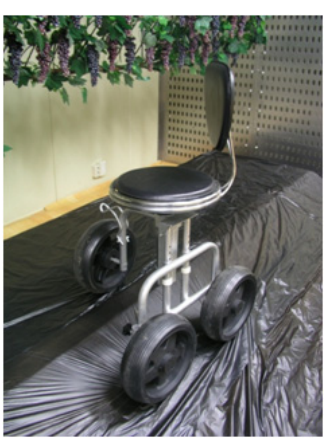

(a)

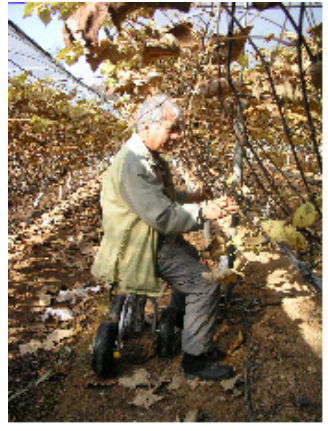

(b)
Figure 2. Working chair for grapevine cluster thinning [(a) laboratory, (b) field in grapevine yard]

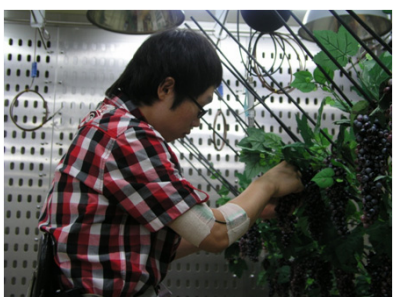

(a)

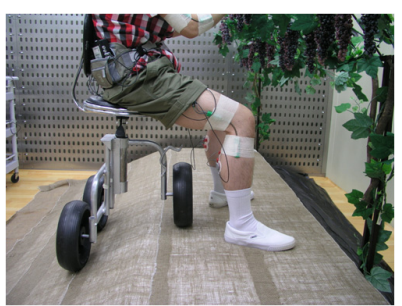

(b)
Figure 3. Attachment of experimental equipment [(a) upper limbs, (b) lower limbs]

테스트를 시행하였고, 실험 종료 후 충분한 휴식을 취한 후 측정하였다(P. Konrad, 2005).

\subsection{Experimental method}

포도 알솎기 작업의자의 생체역학적 작업부담 경감효과를 평가하기 위해 독립변수는 작업의자의 사용 유/무로, 기존의 작업방식과 작업의자를 사용한 작업방식의 두 수준으로 설 계하였다. 종속변수는 근육의 활동도, 작업강도 및 신체불편 도이며, 이를 분석하기 위하여 근전도 신호의 RMS(Root Mean Square) 와 관절 각도를 이용하였다. 또한 피실험자 의 주관적 평가를 위해 신체불편도 평가(Corlett, E.N \& Bishop, R.P., 1976) 와 Borg 스케일(Borg, 1970)을 이용 한 작업강도를 평가하였다.

포도 알속기 작업의자의 생체역학적 작업부담 경감효과를 평가하기 위해 독립변수는 작업의자의 사용 유/무로, 기존의 작업방식과 작업의자를 사용한 작업방식의 두 수준으로 설 계하였다. 종속변수는 근육의 활동도와 신체불편도, 팔꿈치, 몸통 및 무릎 각도이며, 이를 분석하기 위하여 근전도 신호 의 RMS (Root Mean Square)와 팔꿈치, 몸통과 무를 각도 
를 사용하였다. 또한 피험자의 주관적 평가를 위해 신체불편 도 평가(Corlett, E.N \& Bishop, R.P., 1976)를 이용하였다. 통계분석은 SPSS 12.0을 이용하였으며, 통계적 유의수준 은 모든 검정에서 $\alpha=0.05$ 로 분석하였다.
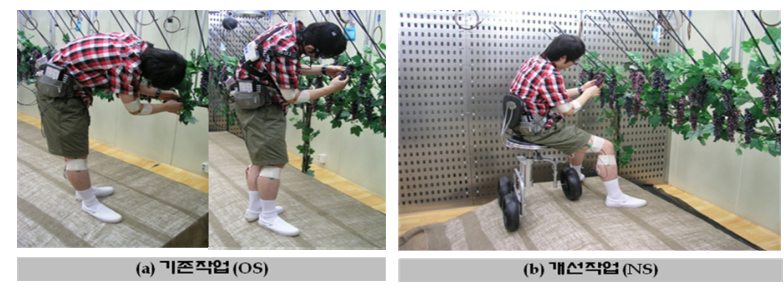

Figure 4. Grapevine cluster thinning

피실험자의 동작은 현장연구를 참조하여 작업방식(기존작 업 및 개선작업) 및 작업속도(송이당 13 초 작업)를 통제하 였고, 실험순서는 휴식시 근전도 신호측정을 위한 휴식구간 (20분), 1차 작업(30분), 중간 휴식(10분), 2차 작업(30분) 및 최종 휴식(20분)으로 구성하였다. 평가방법은 생체역학 적 평가 및 주관 신체불편도 평가를 하였다. 실험은 1 일 1 회 시행하였으며, 작업방식별 2회 반복실험 하였다.

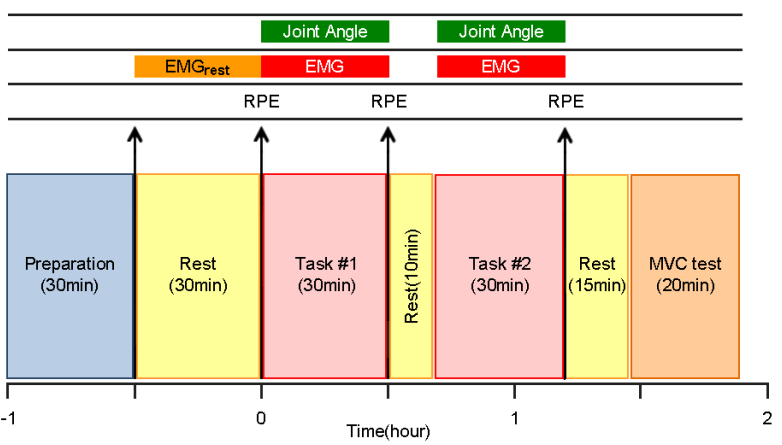

Figure 5. Experimental procedure

\section{Results}

\subsection{Muscle activity}

실험을 통한 피실험자의 근육활동도 측정에서 알속기 작 업의자를 이용한 작업과 기존작업의 상지 및 하지 근육활동 도에 대한 분산분석을 수행하였고, 8 개 근육신호에서 발생 하는 신호를 검출하였다. 검출된 신호에 대한 Normalized $\mathrm{RMS}$ (\%MVC) 값은 [그림 6] 과 같다. 작업의자를 이용에 따른 근육활동도에서는 하지 근육 즉, 대퇴사두근 $(p<0.05)$
과 가자미근 $(p<0.05)$ 이 통계학적으로 유의한 차이를 보여, 상기 두 근육에 대한 작업의자의 사용 후 근육활동도가 감소 함을 알 수 있다. 반면에 상지 근육의 사용은 커지는 경향을 보여주었다. 이는 입식자세에서의 허리를 구부린 기존작업 이 작업대상물과의 거리를 좁혀 어깨 근육의 부담은 줄이고, 하지 근육에서의 근육활성도는 높이기 때문이다. 반면에 개 선작업은 작업의자를 이용하여 하지 근육 사용을 줄이지만, 앉은 상태에서 작업대상물까지의 거리가 관행방식에 비해 상대적으로 멀어 팔을 더 뻗거나 허리를 숙여야 하므로 상 지 및 요추부 근육의 사용이 증가하였다.

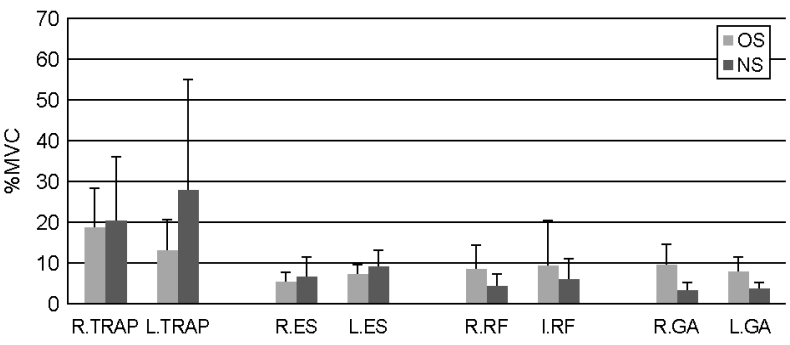

Figure 6. EMG activity of 8 muscles during grapevine clustering thinning [OS, 기존작업; NS, 개선작업]

\subsection{Range of motion in elbow, trunk and knee joint}

실험을 통한 피실험자의 관절운동 평가에서 기존작업 $(\mathrm{OS})$ 과 알솎기 작업의자를 사용한 개선작업 $(\mathrm{NS})$ 시 작업자 의 관절각 요인에 대한 분석분석 결과는 [표 2] 와 같고, 허 리 $(p<0.05)$ 와 무릎관절 $(p<0.05)$ 에서 통계적으로 유의한 차이를 보였다. 허리 굽힘/신전운동 및 무릎 굽힘/신전운동 은 기존작업과 개선작업에서 각각 평균 $45.11,32.77$ 도와 $15.05,62.50$ 도로, 허리운동은 개선작업을 통해 관절운동 범위를 줄이는 것으로 평가되었고, 무릎운동 범위는 작업의 자를 이용한 개선작업이 앉아서 작업을 하게 되어 무릎을 더 굽게 되므로 큰 운동 범위를 보이는 것으로 평가되었다. 팔꿈치 관절운동에서는 통계학적으로 유의한 차이를 보이지 않았다.

작업의자를 이용한 개선방식의 경우 허리와 무릎관절에 서의 가동 범위가 관행방식에 비해 줄어들고, 허리를 굽힌 각도 또한 줄어 들었다. 포도 알솎기 작업이 장시간 동안 반 복적으로 수행되는 작업특성에 비추어 볼 때 관절가동 범위 의 감소는 허리나 하지 부위의 불편도 및 근골격계 위험 도를 저감시켜 줄 것으로 판단된다. 
Table 2. Range of motion during grapevine cluster thinning

\begin{tabular}{c|r|r|r|r|c|c}
\hline \multirow{2}{*}{ Variables } & \multicolumn{2}{|c|}{ Elbow } & \multicolumn{2}{c|}{ Trunk $^{*}$} & \multicolumn{2}{c}{ Knee $^{*}$} \\
\cline { 2 - 7 } & OS & NS & OS & NS & OS & NS \\
\hline \multicolumn{7}{c}{ Positions (percentile ${ }^{\circ}$} \\
\hline \multicolumn{7}{c}{ Flexion } \\
\hline 10th & 4.98 & 9.89 & 51.88 & 50.59 & 83.06 & 97.93 \\
\hline 50th & -48.14 & -43.39 & 45.11 & 32.77 & 15.05 & 62.50 \\
\hline 90th & -80.33 & -80.23 & -13.07 & -8.83 & -6.80 & -4.07 \\
\hline \multicolumn{7}{c}{ Lateral Flexion } \\
\hline 10th & - & - & 20.40 & 23.27 & - & - \\
\hline 50th & - & - & 3.31 & 3.61 & - & - \\
\hline
\end{tabular}

\subsection{Subjective evaluation}

실험을 통한 피실험자의 주관적 작업강도와 신체불편도 평가에서 기존작업 $(\mathrm{OS})$ 과 알속기 작업의자를 사용한 개선 작업(NS)시 피험자가 느끼는 신체 부위별 불편도에 대한 분산분석을 수행한 결과는 [표 3] 과 같다. 작업전 작업자가 느끼는 불편도는 차이가 나지 않았다. 작업의자를 이용한 개 선작업이 허리 부위 $(p<0.05)$ 및 대퇴부 부위 $(p<0.05)$ 의 불편도를 감소시켜 주는 것으로 평가되었다. 하지만 목과 어깨 부위의 불편도는 감소하지 않았다. 의자를 이용한 개선 작업의 경우 작업의자 좌판의 쿠션이 충분치 못하여, 작업시 간이 늘어날 경우 불편을 호소하는 경우가 발생하였다. 기존 작업과 알속기 작업의자를 사용한 개선작업시 작업자의 주 관적 작업강도는 [표 4] 와 같다. 실험 시작 전, 피험자들이 느끼는 힘들기는 차이는 없었다. 하지만 기존작업(OS) 과 개 선방식 $(\mathrm{NS})$ 의 힘들기는 작업 1 에서 $12.75,11.58$, 작업 2 에서 $14.0,12.42$ 로 차이가 각각 통계학적으로 유의한 범위 내에서 힘들기 차이가 났다 $(p<0.05 ; p<0.05)$.

Table 3. Body part discomfort during grapevine cluster thinning

\begin{tabular}{|c|c|c|c|c|c|c|c|c|c|c|c|c|}
\hline \multirow{3}{*}{$\begin{array}{l}\text { Body } \\
\text { Region }\end{array}$} & \multicolumn{6}{|c|}{ Old Type } & \multicolumn{6}{|c|}{ New Type } \\
\hline & \multicolumn{2}{|c|}{ Rest } & \multicolumn{2}{|c|}{ Task\#1 } & \multicolumn{2}{|c|}{ Task\#2 } & \multicolumn{2}{|c|}{ Rest } & \multicolumn{2}{|c|}{ Task\#1 } & \multicolumn{2}{|c|}{ Task\#2 } \\
\hline & $\mathrm{L}$ & $\mathrm{R}$ & $\mathrm{L}$ & $\mathrm{R}$ & $\mathrm{L}$ & $\mathrm{R}$ & $\mathrm{L}$ & $\mathrm{R}$ & $\mathrm{L}$ & $\mathrm{R}$ & $\mathrm{L}$ & $\mathrm{R}$ \\
\hline Neck & 0 & - & 58.33 & - & 58.33 & - & 0 & 0 & 58.33 & - & 41.67 & - \\
\hline Shoulder & 0 & 0 & 8.33 & 41.67 & 0 & 66.67 & 0 & 0 & 8.33 & 83.33 & 0 & 58.33 \\
\hline Upper arm & 0 & 0 & 0 & 41.67 & 0 & 41.67 & 0 & 0 & 0 & 41.67 & 0 & 16.67 \\
\hline Elbow & 0 & 0 & 0 & 0 & 0 & 0 & 0 & 0 & 0 & 0 & 0 & 0 \\
\hline Forearm & 0 & 0 & 0 & 0 & 0 & 0 & 0 & 0 & 0 & 0 & 0 & 0 \\
\hline Wrist & 0 & 0 & 0 & 33.33 & 0 & 25.00 & 0 & 0 & 0 & 16.67 & 0 & 25.00 \\
\hline Upper back & 0 & 0 & 8.33 & - & 8.33 & & 0 & 0 & 25 & - & 16.67 & - \\
\hline Mid back & - & - & - & - & - & - & - & - & - & - & - & - \\
\hline
\end{tabular}

Table 3. Body part discomfort during grapevine cluster thinning (Continued)

\begin{tabular}{|c|c|c|c|c|c|c|c|c|c|c|c|c|}
\hline \multirow{3}{*}{$\begin{array}{l}\text { Body } \\
\text { Region }\end{array}$} & \multicolumn{6}{|c|}{ Old Type } & \multicolumn{6}{|c|}{ New Type } \\
\hline & \multicolumn{2}{|c|}{ Rest } & \multicolumn{2}{|c|}{ Task\#1 } & \multicolumn{2}{|c|}{ Task\#2 } & \multicolumn{2}{|c|}{ Rest } & \multicolumn{2}{|c|}{ Task\#1 } & \multicolumn{2}{|c|}{ Task\#2 } \\
\hline & $\mathrm{L}$ & $\mathrm{R}$ & $\mathrm{L}$ & $\mathrm{R}$ & $\mathrm{L}$ & $\mathrm{R}$ & L & $\mathrm{R}$ & $\mathrm{L}$ & $\mathrm{R}$ & $\mathrm{L}$ & $\mathrm{R}$ \\
\hline Lower Back & 0 & - & 100 & - & 100 & - & 0 & - & 41.67 & - & 50 & - \\
\hline Buttocks & 0 & 0 & 16.67 & - & 41.67 & - & 0 & 0 & 8.33 & - & 25.00 & - \\
\hline Hip & 0 & 0 & 0 & 0 & 0 & 0 & 0 & 0 & 0 & 0 & 0 & 0 \\
\hline Thighs & 0 & 0 & 16.67 & 16.67 & 33.3 & 25.00 & 0 & 0 & 0 & 0 & 0 & 0 \\
\hline Knee & 0 & 0 & 0 & 8.33 & 0 & 25.00 & 0 & 0 & 0 & 0 & 8.33 & 0 \\
\hline Legs & 0 & 0 & 16.67 & 0 & 25.00 & 8.33 & 0 & 0 & 0 & 0 & 0 & 0 \\
\hline Ankle & 0 & 0 & 0 & 0 & 0 & 0 & 0 & 0 & 0 & 0 & 0 & 0 \\
\hline Foot & 0 & 0 & 0 & 0 & 0 & 0 & 0 & 0 & 0 & 0 & 0 & 0 \\
\hline
\end{tabular}

Table 4. Subjective physical workload during grapevine cluster thinning

\begin{tabular}{|c|c|c|c|}
\hline \multirow{2}{*}{$\begin{array}{l}\text { Whole body RPE } \\
\text { (Borg, 1970) }\end{array}$} & Rest & Task \#1 ${ }^{*}$ & Task \#2 $2^{* *}$ \\
\hline & $\begin{array}{l}\text { Mean } \\
(\mathrm{SD})\end{array}$ & $\begin{array}{c}\text { Mean } \\
(\mathrm{SD})\end{array}$ & $\begin{array}{c}\text { Mean } \\
(\mathrm{SD})\end{array}$ \\
\hline 기존작업(OS) & $9.25(1.08)$ & $12.75(0.69)$ & $14.00(0.71)$ \\
\hline 개선작업(NS) & $8.42(0.80)$ & $11.58(1.32)$ & $12.42(0.58)$ \\
\hline
\end{tabular}

\section{Conclusion}

본 연구에서는 기존의 포도 알속기 작업과 포도 알솎기 작업의자를 이용한 개선작업을 생체역학적인 방법으로 비교, 평가하였다. 그리고 근전도를 이용한 근육활동도 평가, 관절 각을 이용한 생체역학적 평가, 작업강도 및 신체불편도를 이 용한 주관적인 평가를 이용하여 작업의자의 작업부담 경감 효과를 정량적으로 평가하였으며, 향후 요구되는 보완점을 고찰하였다.

작업의자를 이용한 개선방식은 하지 부위의 근육활동을 줄여줄 뿐만 아니라 허리의 굽힘 운동과 무릎관절의 반복적 인 굽힘, 신전운동을 줄여주어 하지 부위의 작업부담을 줄여 주었다. 또한 작업자가 느끼는 작업강도도 낮춰주었으며, 특 히 대퇴부, 정강이부와 허리 부위에 느끼는 불편함을 줄여주 는 것으로 평가되었다. 하지만 작업의자를 이용한 개선작업 은 상지 부위의 근육 부담을 높였다. 또한 작업의자 쿠션이 충분치 못하여 엉덩이 부위에 느끼는 불편감이 추가적으로 보고되었다. 추후에는 의자 좌판 및 등받이에 대한 추가적인 보완을 통해 편의성을 향상시키는 작업이 필요하다.

본 연구는 포도작업장 계측을 통해 유사한 작업을 실험실 
내에 설치하고, 작업시간을 30 분으로 국한시킨 실험이라는 점과 신체, 건강한 성인 남성을 대상으로 한 실험이라는 점 에서 연구의 한계점이 있다. 따라서 추후에는 포도 작업장에 서의 실제 작업자를 대상으로 한 작업 평가를 통해 추가적인 평가결과에 대한 검증실험이 수행되어야 하며, 인간공학적 측면에서 포도 알솎기 작업의자의 작업효율에 대한 평가도 추후 필요하다.

\section{Acknowledgements}

This study was carried out with the support of "Research Program for Agricultural Science \& Technology Development (Project No. 006422)", National Academy of Agricultural Science, Rural Development Administration, Republic of Korea.

\section{References}

Kim, K. R., A study on the farmers' health status and musculoskeletal workload, Ph.D. thesis, Seoul National University, Seoul, South Korea, 2008

Kim, K. W., Chai, H. S. and Lee, K. S., "The Study on the Improvement of Grape Heading Work through Working Chair of Rail-Drift", Proc. Spring Conf. the Ergonomics Society of Korea, (pp.28-33), Suwon, Korea, 2008

Kim, H. N. and Hwang, K. M., A study on the current labor of female farmers, RLSI Research Report, 1991.

RDA, Report on comparison and analysis for main disease and health status in farmer and fisherman, Suwon, South Korea, Publ. No. 11-1390093-000107-01, National Academy of Agricultural Science, Suwon, South Korea, 2004.

RRDI, Prevention for agricultural injuries and diseases and safety management program, 2006.

RRDI, Musculoskeletal risk factors and high risky works on 12 type of crops through video analysis, 2006.

Lee, Y. H., Lee, J. H., Lee, K. S., Kim, K. R. and Lee, S. J., Ergonomic risk factors related to musculoskeletal symptoms in the vineyard workers, J Korean Soc Occup Environ Hyg, 18(2), 122-132, 2008.

Choi, J. W., Chung, S. T. and Seol, H., Study on farm work environment and physical load in Korea - Focusing on health survey, living behavior, cumulative fatigue symptoms by crops, The Korean Journal of Community living Science, 9(2), 43-50, 1998.

Choi, J. W., Kim, M. J. and Lee, J. Y., Evaluation of farmer's workload and thermal environments during harvesting grape in summer, Journal of the Korea Home Economics Association, 40(11), 1-13, 2002.

Kato, A. E., Fathallah, F. A., Miles, J. A., Meyers, J. M., Faucett, J.,
Janowitz, I. and Garcia, E.G., Ergonomic Evaluation of Winegrape Trellis Systems Pruning Operation. Journal of Agricultural Safety and Health, 12(1), 17-28, 2006.

Borg, G. A., Perceived exertion as an indicator of somatic stress, Scand. J. Rehabil. Med., 2, 92-98, 1970.

Corlett, E. N. and Bishop, R. P., A technique for measuring postural discomfort, Ergonomics, 9, 175-182, 1976.

Konrad, P., The ABC of EMG: A practical introduction to kinesiological electromyography. Version 1.0. Apr 2005. Noraxon, Inc, USA.

$\mathrm{NIOSH}$, Selected topics in surface electromyography for use in the occupational setting: Expert perspectives. U.S. Department of Health and Human Services, Centers for Disease Control, March 1992.

Wakula, J., Beckman, T., Hett, M. and Landau, K., Ergonomic analysis of grapevine pruning and wine harvesting to define work and hand tools design requirements, Occup Biomech, 2, 151-161, 2000.

\section{Author listings}

Kyung Suk Lee: leeks81@korea.kr

Highest degree: $\mathrm{PhD}$, Department of Clothing and textiles, Seoul National University

Position title: Senior Researcher, Department of Agricultural Engineering, RDA

Areas of interest: Occupational safety and health, Management system

Hyo Cher Kim: alf0416@ korea.kr

Highest degree: MS, Department of Environmental Health, Seoul National University

Position title: Junior Researcher, Department of Agricultural Engineering, RDA

Areas of interest: Health and safety, Occupational hazard assessment

Hye Seon Chae: hyeseon@korea.kr

Highest degree: B.S, Department of Clothing and textiles, Yeungnam University

Position title: Junior Researcher, Department of Agricultural

Engineering, RDA

Areas of interest: Development of ergonomic agricultural assistive

Kyung Ran Kim: kimgr@korea.kr

Highest degree: $\mathrm{PhD}$, Department of Clothing and textiles, Seoul National University

Position title: Junior Researcher, Department of Agricultural Engineering, RDA

Areas of interest: Musculoskeletal workload, Farmer's health and safety 
Dae Seop Lim: daesup@korea.kr

Highest degree: PhD, Department of Bio-Mechatronics Engineering, Sungkyunkwan University

Position title: Researcher, Department of Agricultural Engineering, RDA

Areas of interest: Ergonomics, Biomechanical analysis, Computer

Simulation, Human modeling
Date Received : 2011-04-26

Date Revised : 2011-05-24

Date Accepted : 2011-05-25 